\section{Energy: social fixes are on the up}

Already governments, environmental agencies, nongovernmental organizations and businesses are on the way to meeting Benjamin Sovacool's call for energy research to be more socially oriented (Nature 511, 529-530; 2014). The annual Behavior, Energy and Climate Change Conference, this year to be held in December, reviews their achievements and ongoing research activities.

Examples of social energy practices include smartphone apps that allow remote control of domestic thermostats and can even track carbon emissions. The US Energy Star programme and the Leadership in Energy and Environmental Design rating systems ensure that buildings are energy-efficient and environmentally sound. Other energy-efficiency initiatives include Japan's Top Runner and the UK Energy Saving Trust.

The US company Opower, which serves 32 million households and businesses, enables consumers to compare their energy usage. Car manufacturers, with help from researchers at the University of California, Davis, are studying drivers' behaviour with a view to creating a display that indicates how to cut fuel consumption. And US start-up companies such as Zipcar, Uber and Lyft are changing consumer relationships with their vehicles by enabling car sharing.

Developing countries are also on the front line of new business models for clean and sustainable energy. The 'en.lighten' initiative, led by the Global Environment Facility, the United Nations Environment Program and industry partners, is accelerating conversion to energy-efficient lighting. In India, the think tank TERI (The Energy and Resources Institute) is leading efforts to provide solar lighting for poor communities and tackling gender issues that might prevent it from being widely accepted. And in Africa, mobile-phone payment systems are making it easier for kerosene consumers to switch to solar energy.

David E. Rodgers, Dustin S. Schinn The Global Environment Facility, Washington DC, USA. dschinn@thegef.org

\section{Energy: we need all hands on deck}

A more interdisciplinary approach will advance our understanding of energy issues (see also B. K. Sovacool Nature 511, 529-530; 2014).

In considering how to improve energy efficiency using a particular technology, for example, an engineering-only analysis would seek to optimize technical efficiency, whereas an engineering-economic analysis would aim to make it more costeffective. But an interdisciplinary analysis would take in wider considerations. For example, convenience to consumers and the attributes of organizations promoting the technology can affect adoption rates by a factor of ten when financial incentives are comparable (P. C. Stern Energy Res. Soc. Sci. 1, 41-48; 2014).

Psychologist Kurt Lewin remarked that "there is nothing so practical as a good theory" (Field Theory in Social Science Harper, 1951). I suggest that nothing advances theory better than tackling a practical problem by integrating different perspectives.

Paul C. Stern National Research Council, Washington DC, USA. pstern@nas.edu

\section{Energy: humanities frame the aims}

Social scientists offer more than just information for producing a best fit between energy technologies and social circumstances (B. K. Sovacool Nature 511, 529-530;
2014). By eliciting different social framings of energy systems and technologies, they help to determine points of commonality and disagreement about the sort of Earth we want to inhabit.

The humanities are concerned with profound questions about justice, fairness, responsibility and care. Such questions can no longer be regarded as external to the design of energy devices and systems because they are central to the entire social and technical fabric of modern society (see, for example, N. Castree et al. Nature Clim. Change 4, 763-768; 2014). Noel Castree University of Wollongong, Australia; and University of Manchester, UK. ncastree@uow.edu.au

\section{Better monitoring of fish in dam projects}

Inadequate ecological monitoring before and after removal of dams in the northwestern United States is hampering evaluation of the success of dozens of these projects (see Nature 511, 521-523; 2014).

A primary purpose of dam removal in the region has been to revive populations of endangered migrating salmonid fish by restoring natural river functions. Populations are being monitored after demolition of the 38-metre Condit dam and 64-metre and 33-metre Elwha dams, but these are exceptions.

Using fish ladders, salmonids were able to ascend the Marmot and Hemlock dams you mention and move into the upper river. But to gauge the ecological impact of such dam removals, it is necessary to have baseline data on fish passage from before the structure was destroyed. In most other cases, these data are not available, thwarting future assessments.

Long-term ecological evaluation and monitoring must be built into dam-removal projects. Otherwise, millions of dollars will continue to be spent with no evidence that the desired outcome is being achieved.

Peter Brewitt, Karen D. Holl University of California, Santa Cruz, USA.

pbrewitt@ucsc.edu

\section{Seals collect more Southern Ocean data}

Marine mammals equipped with recording devices can help to overcome the practical challenges of collecting year-round physical data in the Southern Ocean (see M. C. Kennicutt II et al. Nature 512, 23-25; 2014).

Data collection using satellite remote sensing or surface research vessels, for instance, is limited to the short summer period for access to high latitudes or to the northerly margins of winter sea ice.

By contrast, small oceanographic sensors worn by seals can provide high-resolution oceanographic profiles from Antarctica throughout the winter (see, for example, F. Roquet et al. Scientific Data, in the press). The data can be used to study and map ocean fronts and to monitor the annual formation and growth rate of sea ice (J.-B. Charrassin et al. Proc. Natl Acad. Sci. USA 105, 11634-11639; 2008).

Data derived using seals can help us to predict rapid changes and their effects in the Southern Ocean. This would give the global community time to develop adaptation policies. Clive R. McMahon Sydney Institute of Marine Science, New South Wales, Australia.

Robert Harcourt Macquarie University, Sydney, Australia. clive.mcmahon@utas.edu.au

CONTRIBUTIONS

Correspondence may be submitted to correspondence@nature. com after consulting the guidelines at http:// go.nature.com/cmchno. 